\title{
PENGARUH WORK-FAMILY CONFLICT TERHADAP STRAIN PADA WANITA DEWASA MUDA
}

\author{
Willy Tasdin ${ }^{1}$ dan Nisfianoor ${ }^{2}$ \\ ${ }^{1}$ Fakultas Psikologi, Universitas Tarumanagara Jakarta \\ Email:willyt@fpsi.untar.ac.id \\ ${ }^{2}$ Program Studi Psikologi, Universitas Tarumanagara Jakarta
}

\begin{abstract}
ABSTRAK
Work-family conflict adalah konflik peranan yang terjadi karena benturan peranan yang harus dipenuhi seseorang dalam pekerjaan dan kehidupan pribadi Work-family conflict terbagi menjadi empat dimensi yaitu negative WHI, negative HWI, positive WHI dan positive HWI. Work-family conflict dapat menjadi hambatan terutama bagi wanita dewasa muda yang baru menjalani kehidupan keluarga sehingga stress dapat dialami dan psychological strain dapat dialami. Psychological strain adalah reaksi terhadap stress yang dapat memberikan pengaruh pada aspek psikologis. Tujuan penelitian ini adalah untuk mengetahui pengaruh work-family conflict terhadap psychological strain pada wanita dewasa muda di Jakarta dengan menggunakan teknik sampling convenience yang dilakukan sejak bulan Februari hingga Juni. Hasil penelitian menunjukkan bahwa work-family conflict memiliki pengaruh yang signifikan terhadap psychological strain dengan nilai $\mathrm{F}=45,675$ dan $\mathrm{p}<0,01$. Negative WHI memiliki pengaruh yang signifikan terhadap work-family conflict dengan $\mathrm{t}=5,118$ dan $\mathrm{p}<0,01$ dan Negative $H W I$ memiliki pengaruh yang signifikan terhadap work-family conflict dengan $\mathrm{t}=5,999$ dan $\mathrm{p}<0,01$. Sedangkan positive WHI tidak memiliki pengaruh terhadap psychological strain dengan $\mathrm{t}=-0,427$ dan $\mathrm{p}>0,05$ dan positive HWI tidak memiliki pengaruh terhadap psychological strain dengan $\mathrm{t}=-1,320$ dan $\mathrm{p}>0,05$.
\end{abstract}

Kata Kunci: work-family conflict, psychological strain, wanita dewasa muda.

\section{ABSTRACT}

Work-family conflict occurs due to the conflict of roles that must be fulfilled by an individual in his/her work and personal life. Work-family conflict is divided into four dimensions, namely negative WHI, negative HWI, positive WHI and positive HWI. Work-family conflict can be a barrier especially for young adult women who are beginning to experience family life resulting in stress and psychological strain. Psychological strain is a reaction to stress that can affect psychological aspects. The purpose of this study is to determine the effect of work-family conflict on psychological strain among young adult women in Jakarta using convenience sampling technique conducted from February to June. The result shows that work-family conflict has a significant effect on psychological strains with a value of $F=45.675$ and $p<0.01$. Negative WHI has a significant effect on work-family conflict with $t=5,118$ and $p$ $<0.01$ and Negative HWI has a significant effect on work-family conflict with $t=5,999$ and $p<0.01$. Whereas positive WHI has no influence on psychological strain with $t=-0.427$ and $p>0.05$ and positive HWI has no effect on psychological strain with $t=-1.320$ and $p>0.05$.

Keywords: work-family conflict, psychological strain, young adult women

\section{PENDAHULUAN}

\section{Latar belakang}

Dalam kehidupan seseorang pasti memiliki tekanan atau strain. Osipow dan Spokane (dalam Layne, 2001) mengidentifikasi terdapat 4 tipe dari strain, yaitu: (1) vocational, (2) psychological, (3) interpersonal, dan (4) physical. Psychological Strain mengukur tingkat dari masalah psikologis dan/atau emosional yang dialami oleh individu (Osipow, dalam Layne, 2001). Strain dapat menyebabkan burnout, kecemasan, dan gangguan fisiologis seperti tekanan darah tinggi atau penyakit jantung (Landy \& Conte, 2007).

Vocational strain mengukur tingkat masalah yang dimiliki individu dalam kualitas pekerjaan dan hasilnya dan sikap terhadap pekerjaan juga diukur (Osipow, dalam Jackson, 2004; Layne, 2001). Dalam sebuah penelitian pada perempuan dalam berbagai pekerjaan, kepuasan kerja secara 
signifikan berhubungan dengan level role strain yang rendah (Hemmenlgarn \& Laing dalam Jackson, 2004).

Psychological strain mengukur tingkat masalah psikologis dan emosional yang sedang dialami oleh individu (Osipow, dalam Layne, 2001; Jackson, 2001). Ketidakcukupan peranan, batasan peranan, dan pembagian tanggung jawab ditemukan oleh Osipow \& Davis (dalam Jackson, 2004) memiliki kontribusi pada psychological strain pada mahasiswa. Psychological strain meliputi efek kognisi, seperti ketidakmampuan untuk berkonsentrasi dan ketidakpuasan pekerjaan, gangguan afeksi termasuk keadaan kesehatan mental seperti kecemasan dan depresi mungkin tidak dapat diklasifikasikan dibawah sistem klasifikasi psikiatri yang dikenal namun tetap signifikan sebagai gangguan fungsional atau berbahaya bagi perkembangan gangguan klinis (Sauter, el al., dalam Dollard, Winefield, dan Winefield., 2001).

Interpersonal strain mengukur tingkat gangguan seseorang seperti withdrawal atau agresivitas dalam hubungan interpersonal (Osipow, dalam Jackson, 2004; Layne, 2001). Osipow dan Davis (dalam Jackson, 2004) menemukan bahwa banyaknya peranan, batas peranan, dan tanggung jawab sebagai prediktor yang paling baik dalam interpersonal strain. Physical strain mengukur keluhan mengenai sakit fisik dan kebiasaan self-care yang buruk (Osipow, dalam Jackson, 2004; Layne, 2001). Pada konselor, ambiguitas peranan berhubungan positif dengan beberapa simtom fisik (Pendergast, dalam Jackson, 2004).

Strain yang tinggi dapat memberi pengaruh negatif pada kehidupan seseorang. Pada polisi, strain yang tinggi pada awal dan akhir dari jam kerja dapat menyebabkan mereka lebih rentan terhadap disonansi emosional (Gelderen, Heuven, Veldhoven, Zeelenberg, \& Croon, 2007). Stress yang diakibatkan tuntutan pekerjaan dan keluarga lebih berat bagi wanita dibandingkan pria (Papalia, Sterns, Duskin-Feldman, \& Camp, 2007). Adanya tuntutan ini menyebabkan timbulnya workhome interaction atau work-family conflict, yang menurut Geurts, Taris, Kompier, Dikkers, VanHooff, dan Kinnunen (2005) merupakan sebuah proses dimana fungsi pekerja (perilaku) dalam sebuah ruang lingkup pribadi (misal rumah) dipengaruhi oleh reaksi (positif atau negatif) yang dibentuk di ruang lingkup lainnya. Menurut Masclach \& Jackson (dalam Hoogendoorn, Bongers, De Vet, Houtman, Ariëns, Van Mechelen, \& Bouter, 2001) karakteristik pekerjaan sosial meningkatkan psychological strain, seperti kelelahan emosional, yang mungkin meningkatkan ketegangan otot atau ekskresi hormon

Menurut Reggio (2009) stress dalam pekerjaan dapat disebabkan oleh dua faktor yaitu dari organisasi dan individu, dan salah satu dari sumber stress yang berasal dari organisasi adalah work-family conflict yang terjadi karena usaha untuk menyeimbangkan antara permintaan dari peranan pekerjaan dan keluarga atau kehidupan di luar pekerjaan. Istilah yang sering digunakan untuk work-home interaction disebut sebagai work-family conflict, yang menurut Greenhaus dan Beutell (dalam Sanz-Vergel, et al., 2011) adalah bentuk dari konflik peranan yang masingmasing memiliki tekanan dari pekerjaan dan keluarga. Stres atau konflik terjadi karena seseorang kehilangan, terancam, atau gagal untuk memberikan antisipasi dalam proses kehidupan keluarga dan rumah tangga (Grandey \& Cropanzano, dalam Langballe, Innstrand, \& Aasland, 2010).

Sebuah penelitian yang dilakukan oleh Jansen, Kant, Kristensen, dan Nijhuis menyatakan bahwa work-family conflict berhubungan dengan kebutuhan yang tinggi untuk pemulihan seperti tingkat kelelahan yang tinggi (Moreno-Jimenez, Mayo, Sanz-Vergel, Geurts, Rodriguez, \& Garrosa, 2008). Geurts, et al. (2005) menemukan empat jenis interaksi yaitu: (a) WHI negatif, yaitu reaksi negatif yang berkembang di tempat kerja yang menghambat fungsi di rumah; (b) HWI negatif, 
yaitu reaksi negatif yang berkembang di rumah yang menghambat fungsi di tempat kerja; (c) WHI positif, yaitu reaksi positif yang berkembang di tempat kerja yang memfasilitasi fungsi di rumah, dan (d) HWI positif, yaitu reaksi positif yang berkembang di rumah yang memfasilitasi fungsi di tempat kerja.

Dari penelitian Pattusamy dan Jacob (2017) dikatakan bahwa dukungan keluarga membantu individu mengurangi gangguan pada pekerjaan yang disebabkan oleh keluarga. Adanya dukungan dari anggota keluarga dan pasangan dapat meningkatkan kepuasan seseorang di dalam keluarganya, sehingga membawa keseimbangan pada pekerjaan dan kehidupan berkeluarga. Perempuan bekerja untuk beberapa alasan, seperti: (1) tekanan inflasi dan meningkatnya standar hidup telah bergabung dan membawa perempuan untuk bekerja, (2) semenjak perang dunia dua, gaji telah meningkat (disesuaikan dengan inflasi) dan biaya yang dibutuhkan untuk tinggal di rumah bersama keluarganya bertambah sehingga memaksa lebih banyak perempuan untuk bekerja, (3) jumlah pekerjaan yang disediakan untuk perempuan telah bertambah banyak, (4) penolakan untuk melahirkan lebih awal, (5) peningkatan pendidikan, (6) sikap terhadap aturan bahwa peranan perempuan adalah di rumah telah berubah, dan (7) pada masa depan, angka kelahiran yang menurun akan mengurangi kesediaan pekerja sehingga perempuan berperan penting dalam menjaga kecukupan pekerja (Cox, 2009).

Cukup banyak perempuan yang mengalami tekanan dalam tempat kerja (Papalia, Et al., 2007).Hal ini terjadi karena wanita memiliki tanggung jawab untuk mengatur rumah tangga dan suami mereka. Berdasakan penelitian Grandey, Cordeiro, \& Crouter (dalam Soeharto, 2010) konflik pekerjaan yang dialami istri akan lebih mempengaruhi kepuasan kerja daripada konflik pekerjaan-keluarga (WFC) yang dialami suami. Hal ini terjadi karena konsep yang berorientasi gender membuat peran berbeda antara pria dan wanita, pria berperan di sektor publik sedangkan wanita di sektor domestik (Soeharto, 2010). Pada kasus tertentu wanita dituntut untuk selalu mengurusi keluarga mereka, namun mereka memiliki keinginan untuk dapat membantu ekonomi keluarga. Di sisi lain, wanita yang bekerja juga harus mengurusi pekerjaan mereka.

Meskipun individu dapat menciptakan strategi untuk mengatur kesibukan pekerjaan dan kehidupan berkeluarga, bantuan dari luar seperti pekerja dan pemerintah juga dibutuhkan. Individu sendiri tidak dapat mendesain pekerjaan mereka agar sesuai dengan kebutuhan keluarga mereka (Strong, DeVault, \& Cohen, 2011). Family Policies adalah sekumpulan kebijakan yang mengarahkan family well being dan merupakan upaya pemerintah untuk mencapai hal tersebut (Strong, DeVault, \& Cohen, 2011).

Dalam Papalia, Olds, dan Duskin-Feldman (2009) dikatakan bahwa usia dewasa muda berawal dari usia 20 tahun hingga 40 tahun. Menurut Arnett (Papalia, et al., 2009) terdapat tiga kriteria yang mendefinisikan kedewasaan, yaitu: (a) menerima tanggung jawab sendiri, (b) membuat keputusan sendiri, dan (c) menjadi mandiri dalam hal finansial. Pada wanita biasanya jalan untuk menjadi dewasa adalah pernikahan, yang biasanya terjadi setelah mereka menemukan pasangan yang tepat (Papalia, et al., 2009).

Jeffrey Arnett (dalam Santrock, 2008, 2009) baru-baru ini menyimpulkan terdapat lima kunci karakteristik menjadi dewasa. Pertama adalah identity exploration terutama pada cinta dan pekerjaan. Menjadi dewasa adalah waktu ketika kunci perubahan dalam identitas terjadi pada banyak individu. Kedua adalah instability. Perubahan kehidupan biasanya terjadi ketika masa dewasa, waktu ketika biasanya terjadi ketidakstabilan pada percintaan, pekerjaan, dan pendidikan. Ketiga adalah self-focused. Menjadi dewasa menurut Arnett adalah berfokus pada 
bahwa mereka memiliki sedikit dalam kewajiban sosial, sedikit pekerjaan, dan komitmen kepada orang lain, yang memberikan lebih banyak kebebasan dalam menjalani hidup mereka sendiri.

Ke empat adalah feeling in between. Banyak orang yang menjadi dewasa tidak menganggap diri mereka sebagai remaja maupun orang dewasa sepenuhnya. Kelima adalah the age of possibilities, yaitu waktu ketika individu memiliki kesempatan untuk mengubah hidup mereka. Arnett mengatakan 2 jalur kemungkinan dalam menjadi dewasa, pertama banyak orang yang menjadi dewasa optimis tentang masa depan mereka dan kedua adalah untuk orang yang menjadi dewasa yang mengalami banyak kesulitan ketika mereka tumbuh dan mereka memliki kesempatan untuk mengarahkan hidup mereka menjadi lebih positif. Berdasarkan fenomena di atas, maka dilakukan penelitian untuk melihat "Pengaruh Work-Family Conflict Terhadap Strain Pada Wanita Dewasa Muda."

Rumusan masalah dari penelitian ini adalah apakah work-family conflict memengaruhi strain pada wanita dewasa muda yang bekerja. Hipotesa dalam penelitian ini adalah bahwa work-family conflict berpengaruh terhadap strain wanita dewasa muda yang bekerja

\title{
2. METODE PENELITIAN
}

Analisis data dalam penelitian ini menggunakan teknik regresi yang bersifat non-eksperimental. Populasi dalam penelitian ini adalah wanita dewasa muda yang sudah menikah dan memiliki anak serta bekerja di wilayah DKI Jakarta. Sampel yang diambil dalam penelitian ini sebanyak 287 perempuan, yang jenis pekerjaannya adalah guru atau dosen, karyawan perusahaan, sales promotion girl (SPG), perawat, dan konselor atau psikolog. Namun, terdapat 100 subyek yang tidak memenuhi kriteria. Pemilihan subyek menggunakan non-probability sampling dengan teknik convenience sampling.

\begin{abstract}
Alat ukur
Work-family conflict diukur menggunakan The SWING yang diciptakan oleh Geurts, et al (2005) yang terdiri dari 27 item dan terdiri dari 4 dimensi yang masing-masing terdiri dari beberapa pernyataan. Dimensi dari work-family conflict adalah negative WHI yang terdiri dari sembilan item, negative HWI yang terdiri dari enam item, positive WHI yang terdiri dari enam item, dan positive $H W I$ yang terdiri dari enam item.
\end{abstract}

Contoh item pada dimensi WHI negatif adalah "Saya mudah tersinggung di rumah karena dituntut oleh pekerjaan." Contoh item pada dimensi HWI negatif adalah "Situasi di rumah membuat saya mudah marah sehingga Saya melampiaskan frustrasi Saya kepada teman kerja Saya." Contoh item pada dimensi WHI positif adalah "Saya pulang ke rumah dengan ceria setelah pekerjaan Saya berjalan lancar, memberikan pengaruh positif terhadap suasana dalam rumah." Contoh item pada dimensi HWI Positif adalah "Setelah menghabiskan waktu dengan Pasangan / keluarga/teman Saya, Saya pergi bekerja dengan suasana hati yang baik, dan memberikan pengaruh positif terhadap suasana di kantor." Pilihan jawaban menggunakan rentang skala $1-5$, dengan skala 1 yang menunjukkan subyek sangat tidak setuju dengan pernyataan tersebut dan skor 5 yang menunjukkan subyek sangat setuju dengan pernyataan tersebut.

Strain diukur menggunakan OSI-R bagian personal strain yang diciptakan oleh Osipow dan digunakan oleh Layne (2001) dan Jackson (2004). OSI-R terdiri dari 40 item yang dibagi menjadi 4 dimensi, yaitu vocational strain yang terdiri dari 10 item, (2) psychological strain yang terdiri dari 10 item, (3) interpersonal strain yang terdiri dari 10 item, dan (4) physical 
strain yang terdiri dari 10 item. Butir dalam alat ukur ini berbentuk rentang skala yang menunjukkan kesesuaian hal-hal yang dialami subyek terhadap pernyataannya. Contoh item pada dimensi vocational strain adalah "Saya tidak dapat menyelesaikan pekerjaan saya". Contoh item pada dimensi psychological strain adalah "Akhir-akhir ini saya mudah merasa tersinggung." Contoh item pada dimensi interpersonal strain adalah "Saya berharap memiliki lebih banyak waktu untuk dihabiskan bersama teman dekat." Contoh item pada dimensi physical strain adalah "Berat badan saya bertambah tidak terencana." Pilihan jawaban menggunakan rentang skala 1-5, yang mencirikan keadaan diri subyek.

\section{Reliabilitas alat ukur}

Pada uji reliabilitas alat ukur The SWING untuk dimensi WHI negatif dengan jumlah sembilan butir diperoleh $\alpha=0.867$. Semua butir memenuhi syarat sehingga tidak ada butir yang dibuang. Pada dimensi HWI Negatif diperoleh nilai $\alpha=0.757$ dengan jumlah enam butir. Semua butir memenuhi syarat sehingga tidak ada butir yang dibuang. Pada dimensi yang ketiga yaitu WHI Positif diperoleh nilai $\alpha=0.784$ dengan jumlah 6 butir. Semua butir memenuhi syarat sehingga tidak ada butir yang dibuang. Pada dimensi yang keempat yaitu HWI Positif diperoleh nilai $\alpha=$ 0.860 dengan jumlah 6 butir. Semua butir memenuhi syarat sehingga tidak ada butir yang dibuang.

Pada uji reliabilitas alat ukur OSI-R untuk dimensi vocational strain dengan jumlah 10 butir diperoleh $\alpha=0.784$. Pada dimensi ini terdapat satu butir yang tidak memenuhi syarat sehingga dibuang, yaitu butir enam. Setelah butir buruk dibuang diperoleh $\alpha=0.809$, dengan jumlah 9 butir. Pada dimensi psychological strain diperoleh nilai $\alpha$ sebesar 0.844 dengan jumlah 10 butir. Pada dimensi ini terdapat satu butir yang tidak memenuhi syarat sehingga dibuang, yaitu butir 19. Setelah butir buruk dibuang diperoleh $\alpha=0.865$, dengan jumlah sembilan butir.

Pada dimensi ketiga yaitu interpersonal strain diperoleh nilai $\alpha$ sebesar 0.766 dengan jumlah 10 butir. Pada dimensi ini terdapat satu butir yang tidak memenuhi syarat sehingga dibuang, yaitu butir 24. Setelah butir buruk dibuang diperoleh $\alpha=0.775$, dengan jumlah sembilan butir. Dimensi keempat yaitu physical strain diperoleh nilai $\alpha=0.810$ dengan jumlah 10 butir. Pada dimensi ini terdapat satu butir yang tidak memenuhi syarat sehingga dibuang, yaitu butir 33 . Setelah butir buruk dibuang diperoleh $\alpha=0.819$, dengan jumlah sembilan butir.

\section{HASIL DAN PEMBAHASAN}

Berdasarkan data yang diperoleh, nilai minimum pada variabel work-family conflict adalah 1.32 dan nilai maksimumnya adalah 3,92. Mean empirik yang didapat pada dukungan sosial adalah 2,8417 dengan standar deviasi 0.38572. Mean hipotetik pada skala ini adalah 3.00 karena menggunakan Skala Likert dengan angka 1 sampai 5. Mean empirik 2,8417<3.00 mean hipotetik sehingga work-family conflict pada subyek cenderung rendah.

Berdasarkan data yang diperoleh, nilai minimum pada variabel strain adalah 1.08 dan nilai maksimum adalah 3,81. Mean empirik yang didapat pada dukungan sosial adalah 2,3736 dengan standar deviasi 0.52273. Mean hipotetik pada skala ini adalah 3.00 karena menggunakan Skala Likert dengan angka 1 sampai 5. Mean empirik 2,3736 < 3.00 mean hipotetik sehingga strain pada subyek agak rendah. 
Tabel 1. Gambaran Data Penelitian

\begin{tabular}{ccccccc}
\hline Variabel & Min & Max & $\begin{array}{c}\text { Mean } \\
\text { Empirik }\end{array}$ & $\begin{array}{c}\text { Mean } \\
\text { Hipotetik }\end{array}$ & SD & Keterangan \\
\hline $\begin{array}{c}\text { Work-Family } \\
\text { Conflict }\end{array}$ & 1,32 & 3,92 & 2,8417 & 3 & 0,38572 & $\begin{array}{c}\text { Cenderung } \\
\text { Rendah } \\
\text { Cenderung } \\
\text { Rendah }\end{array}$ \\
\hline
\end{tabular}

Berdasarkan analisis yang dilakukan, dimensi negative WHI memiliki nilai $\mathrm{t}=5,118$ dan $\mathrm{p}=$ $0,000<0,05$ (lampiran 7b). Artinya dimensi negative $W H I$ memiliki pengaruh yang signifikan terhadap strain. Berdasarkan analisis yang dilakukan, dimensi negative $H W I$ memiliki nilai $\mathrm{t}=$ 5,999 dan $\mathrm{p}=0,000<0,05$ (lampiran $7 \mathrm{~b}$ ). Artinya dimensi negative HWI memiliki pengaruh yang signifikan terhadap strain.

Tabel 2. Nilai t dan Signifikansi Pengaruh Dimensi

Work-Family Conflict Terhadap Variabel Strain

\begin{tabular}{cccc}
\hline Dimensi & Nilai t & Sig & Keterangan \\
\hline Negative WHI & 5,118 & 0,000 & $\begin{array}{c}\text { Ada pengaruh } \\
\text { signifikan } \\
\text { Ada pengaruh } \\
\text { signifikan }\end{array}$ \\
Negative HWI & 5,999 & 0,000 & $\begin{array}{c}\text { Tidak ada pengaruh } \\
\text { Positive WHI }\end{array}$ \\
Positive HWI & $-0,427$ & 0,670 & Tidak ada pengaruh \\
\hline
\end{tabular}

Berdasarkan analisis yang dilakukan, dimensi positive WHI memiliki nilai $\mathrm{t}=-0,427$ dan $\mathrm{p}=$ $0,670>0,05$ (lampiran 7b). Artinya dimensi positive WHI tidak memiliki pengaruh terhadap strain. Berdasarkan analisis yang dilakukan, dimensi positive $W H I$ memiliki nilai $t=-1,320$ dan $\mathrm{p}=0,189>0,05$. Artinya dimensi positive WHI tidak memiliki pengaruh terhadap strain.

Bila dibuat kesimpulan umum tentang pengaruh work-family conflict terhadap strain, maka nilai $\mathrm{F}=45,675$ dan $\mathrm{p}=0,000<0,01$. H0 ditolak dan H1 diterima. Jadi terdapat pengaruh yang signifikan antara work-family conflict terhadap strain. Besarnya $\mathrm{R}$ Square $=0,501$, artinya sumbangan work-family conflict terhadap strain adalah sebesar 50,1 persen sedangkan sisanya 49,9 persen dipengaruhi faktor lain.

Pada variabel work-family conflict, negative WHI dan negative HWI lebih berpengaruh terhadap strain dilihat dari nilai beta sebesar negative $W H I=0,335$ dan negative $H W I=0,406$, dibandingkan dengan faktor lain seperti positive $W H I=-0,033$ dan positive $H W I=-0,103$.

\section{KESIMPULAN DAN SARAN}

Berdasarkan hasil yang diperoleh dari analisis data utama, hipotesis penelitian diterima, yaitu work-family conflict memiliki pengaruh yang signifikan terhadap strain pada wanita dewasa muda dan pengaruh yang diberikan work-family conflict adalah sebesar 50,1 persen. Diketahui bahwa WHI negatif memiliki pengaruh yang signifikan terhadap strain. HWI negatif juga memiliki pengaruh yang signifikan terhadap strain. Sebaliknya, WHI positif tidak memiliki pengaruh terhadap strain dan HWI negatif juga tidak memiliki pengaruh terhadap psychological strain.

Hasil penelitian ini juga menunjukkan bahwa WHI negatif dan HWI negatif memiliki pengaruh yang signifikan terhadap strain dan WHI positif dan HWI positif tidak memiliki pengaruh. Hal ini sesuai dengan yang dikatakan dalam Riggio (2009) bahwa penyebab stres dalam pekerjaan 
berasal dari organisasi dan individual. Salah satu faktor dari organisasi tersebut adalah faktor peranan, yaitu work-family conflict. Hasil penelitian juga juga sesuai dengan penelitian yang dilakukan oleh Sanz-Vergel, et al. (2011) dengan hasilnya adalah pada preliminary analysis didapatkan bahwa strain secara signifikan berasosiasi dengan home-work interaction dan workhome interaction. Namun, kedua tipe dari interaksi positif tidak berhubungan dengan strain.

Hasil penelitian ini menunjukkan bahwa subyek memiliki nilai konflik yang cenderung rendah sehingga berdasarkan empat jenis interaksi oleh Geurts, et al (2005) subyek memiliki reaksi yang positif subyek di tempat kerja terhadap fungsi di rumah dan reaksi positif di rumah terhadap fungsi di tempat kerja. Menurut Frone (dalam Hill, et al, 2004) konflik keluarga-pekerjaan adalah bentuk interrole conflict, peran yang dituntut dalam pekerjaan dan keluarga akan saling mempengaruhi. Artinya subyek dalam penelitian ini memiliki interrole conflict yang rendah.

Ditemukan juga bahwa subyek memiliki nilai strain yang cenderung rendah sehingga masalah psikologis dan emosional yang dialami oleh individu cenderung rendah. Seperti yang dikatakan oleh Osipow (dalam Layne, 2001; Jackson, 2004) bahwa strain direfleksikan sebagai respon afektif dan subyektif dari berbagai tipe dari strain yang berdasarkan penelitian yang telah dilakukan berarti subyek memiliki vocational strain, psychological strain, interpersonal strain, dan physical strain yang cenderung rendah.

Penelitian ini diharapkan memberikan sumbangsih bagi kemajuan Ilmu Psikologi, khususnya psikologi keluarga, agar pada saat pembentukan keluarga suami dan istri dapat membuat pembagian tugas yang jelas antara suami dan istri, dan suami dapat memberikan dorongan dan memahami istri karena tugas-tugasnya. Psikologi perempuan, agar para perempuan yang bekerja dapat memilih jenis pekerjaan yang lebih tepat dengan tuntutan keluarga. Terakhir, psikologi industri organisasi dalam mengatasi stres yang terjadi pada pekerja, terutama pada pekerja wanita yang telah memiliki keluarga. Hal tersebut dapat dilakukan dengan memberikan jenis pekerjaan ataupun waktu yang dipilih untuk bekerja dapat lebih fleksibel seperti freelance agar perempuan dapat menyeimbangkan antara kebutuhan keluarga mereka dengan pekerjaan dan mengurangi beban stres yang dirasakan.

Dalam penelitian lanjutan, diharapkan dapat melihat pengaruh work-family conflict terhadap strain namun dengan subyek yang berbeda. Penulis menyarankan untuk melihat pengaruh tersebut tidak hanya pada satu rentang usia, namun dibandingkan dengan rentang usia dewasa madya. Selain itu subyek yang diteliti tidak hanya sudah menikah dan memiliki anak, tapi subyek yang sudah menikah namun belum memiliki anak juga dapat di ikutsertakan. Selain itu, penelitian mengenai work-family conflict juga dapat diujikan pada variabel yang berbeda, misalnya kepuasan kerja. Dapat pula dilakukan penambahan variabel-variabel yang memiliki indikasi mempengaruhi work-family conflict juga menarik untuk dilakukan bagi pengembangan hasil penelitian selanjutnya. Pada penelitian selanjutnya juga dapat dilakukan dengan menggabungkan metode penelitian kuantitatif dengan kualitatif agar dapat mencari penyebab dan cara-cara yang dilakukan oleh subyek.

\section{Ucapan Terima Kasih (Acknowledgement)}

Penulis mengucapkan terima kasih kepada beberapa pihak yang telah berpartisipasi dalam penelitian ini, yaitu perusahaan-perusahaan, sekolah, dan rumah sakit yang telah memberikan izin untuk membagikan kuesioner kepada karyawannya. Dan terutama kepada para partisipan. 


\section{REFERENSI}

Cox, F. D. (2009). Human intimacy Marriage, the family, and its meaning (ed. 10). Canada: Wadsworth Cengage Learning.

Dollard, M. F., Winefield, H. R., \& Winefield, A. H. (2001). Occupational strain and efficacy in human service workers: When the rescuer becomes the victim. Dordrecht, Netherlands: Kluwe Academic Publishers. http://books.google.co.id/books?id=818YVdOqdwC\&pg=PA15\&dq=Psychological+Strain\&hl=id\&ei=LFiTbKMKZCrrAfP6 6WNAw\&sa=X\&oi=book_result\&ct=result\&resnum=6\&ved=0CEUQ6AEwBQ\#v=onep age $\& \mathrm{q}=$ Psychological $\% 20$ Strain $\& \mathrm{f}=$ false.

Gelderen, B. V., Heuven, E., Veldhoven, M. V., Zeelenberg, M., \& Croon, M. (2007). Psychological strain and emotional labor among police-officers: A diary study. Journal of Vocational Behaviour, 9 (1), 446 - 459. doi: 10.1080/09585192.2016.1138500

Geurts, S. A. E., Taris, T. W., Kompier, M. A. J., Dikkers, J. S. E., Van Hooff, M. L. M., \& Kinnunen, U. M. (2005). Work-home interaction from a work psychological perspective: Development and validation of a new questionnaire, the SWING. Work and Stress, 19(4), 319 - 339. doi: 10.1080/02678370500410208

Hill, E. J., Yang, C., Hawkins, A. J., \& Ferris, M. (2004). A cross-cultural test of the workfamily interface in 48 countries. Journal of Marriage and the Family, 66 (5), 1300-1316. doi: 10.1111/j.0022-2445.2004.00094.x

Hoogendoorn, W. E., Bongers, P. M., de Vet, H. C. W., Houtman, I. L. D., Ariëns, G. A. M., van Mechelen, W., \& Bouter, L. M. (2001). Psychosocial work characteristics and psychological strain in relation to low-back pain. Scand J Work Environ Health 2001, 27(4), 258-267.www.sjweh.fi/download.php?abstract_id=613\&file_nro=1.

Jackson, A. D. (2004). A survey of the occupational stress, psychological strain, and coping resources of licensed professional counselors in virginia: A replication study. http://scholar.lib.vt.edu/theses/available/etd-12212004144456/unrestricted/adjfina letd.pdf.

Landy, F. J., \& Conte, J. M. (2007). Work in the $21^{\text {st }}$ century: An introduction to industrial and organizational psychology (ed. 2). Malden, USA: Blackwell Publishing.

Langballe, E. M., Innstrand, S. T., Aasland, O. G., \& Faklum, E. (2010). The predictive value of individual factors, work-related factors, and work-home interaction on burnout in female and male physicians: A longitudinal study. Stress and Health. John Wiley and Sons, Ltd. doi: $10.1002 /$ smi.1321

Layne, C. M. (2001). The relationship of occupational stress, psychological strain, and coping resources to the turnover intention of rehabilitation counselors. http://scholar.lib.vt.edu/theses/available/etd-10262001104828/ unrestricted/Cmannlayneweb.pdf.

Moreno-Jimenez, B., Mayo, M., Sanz-Vergel, A. I., Geurts, S. Rodriguez-Munoz, A., \& Garrosa, E. (2008). Effects of work-family conflict on employee's well being: The moderating role of recovery experiences. IE Business School Working Paper, CO8-119-1. doi: $10.1037 / \mathrm{a} 0016739$

Papalia, D. E., Olds, S. W., \& Duskin-Feldman, R. (2009). Human development (ed. 11). Avenue of America, New York: McGraw-Hill.

Papalia, D. E., Sterns, H.L., Duskin-Feldman, R., \& Camp, C. J. (2007). Adult development and aging (ed. 3). Avenue of America, New York: McGraw-Hill.

Pattusamy, M. \& Jacob, J. (2017). The mediating role of family-to-work conflict and workfamily balance in the relationship between family support and family satisfaction: A three path mediation approach. Current Psychology, 36, 812-822. doi: 10.1007/s12144-016$9470-y$ 
Reggio, R. E. (2009). Introduction to industrial/organizational psychology (ed. 5). Upper Saddle River, New Jersey: Pearson Education, Inc.

Santrock, J. W. (2008). Essentials of life span development. Avenue of America, New York: McGraw-Hill.

Santrock, J. W. (2009). Life span development (ed. 12). Avenue of America, New York: McGraw-Hill.

Sanz-Vergel, A.I., Demerouti, E., Mayo, M., \& Moreno-Jimenez, B. (2011). Work-home interaction and psychological strain: The moderating role of sleep quality. Applied Psychology: An International Review, 60 (2), 210-230.

Soeharto, T. N. E. D. (2010). Konflik pekerjaan-keluarga dengan kepuasan kerja: Metaanalisis. Jurnal Psikologi, 37 (1), 189-194.

Strong, B., DeVault, C., \& Cohen, T. F. (2011). The marriage and family experience Intimate relationships in a changing society (ed. 11). Canada: Wadsworth Cengage Learning. 